OPEN ACCESS

Edited by:

Bernard Malissen,

Centre d'Immunologie de Marseille

Luminy, France

Reviewed by:

Gottfried Baier,

Medical University of Innsbruck,

Austria

Cosima T. Baldari,

University of Siena, Italy

Alexandre Corthay,

University of Oslo, Norway

${ }^{*}$ Correspondence:

William F. Carson IV

wfcarson@umich.edu

Specialty section:

This article was submitted to T Cell Biology, a section of the journal

Frontiers in Immunology

Received: 20 July 2015 Accepted: 04 November 2015

Published: 20 November 2015

Citation:

Carson WF N, Guernsey LA, Singh A, Secor ER Jr, Wohlfert EA, Clark RB,

Schramm CM, Kunkel SL and Thrall RS (2015) Cbl-b Deficiency in

Mice Results in Exacerbation of Acute and Chronic Stages of Allergic

Asthma.

Front. Immunol. 6:592. doi: 10.3389/fimmu.2015.00592

\section{Cbl-b Deficiency in Mice Results in Exacerbation of Acute and Chronic Stages of Allergic Asthma}

\author{
William F. Carson IV ${ }^{1 *}$, Linda A. Guernsey ${ }^{2}$, Anurag Singh ${ }^{2}$, Eric R. Secor Jr. ${ }^{2}$, \\ Elizabeth A. Wohlfert ${ }^{3}$, Robert B. Clark ${ }^{2}$, Craig M. Schramm ${ }^{4}$, Steven L. Kunkel ${ }^{1}$ and \\ Roger S. Thrall \\ ${ }^{1}$ Department of Pathology, University of Michigan, Ann Arbor, MI, USA, ${ }^{2}$ Department of Immunology, University of \\ Connecticut Health Center, Farmington, CT, USA, ${ }^{3}$ Department of Microbiology and Immunology, University at Buffalo, \\ Buffalo, NY, USA, ${ }^{4}$ Department of Pediatrics, University of Connecticut Health Center, Farmington, CT, USA
}

Mice sensitized to ovalbumin (OVA) develop allergic airway disease (AAD) with short-term daily OVA aerosol challenge; inflammation resolves with long-term OVA aerosol exposure, resulting in local inhalational tolerance (LIT). Cbl-b is an E3 ubiquitin ligase involved with CD28 signaling; Cbl- $b^{-/}$effector $\mathrm{T}$ cells are resistant to regulatory $\mathrm{T}$ cell-mediated suppression in vitro and in vivo. The present study utilized $\mathrm{Cbl}^{-\mathrm{b}^{-/-}}$mice to investigate the role of Cbl-b in the development of AAD and LIT. Cbl-b $\mathrm{b}^{-/-}$mice exhibited increased airway inflammation during $A A D$, which failed to resolve with long-term OVA aerosol exposure. Exacerbation of inflammation in $\mathrm{Cbl}^{-\mathrm{b}^{-/}}$mice correlated with increased proinflammatory cytokine levels and expansion of effector T cells in the BAL during AAD, but did not result in either a modulation of lymphocyte subsets in systemic tissues or in OVA-specific IgE in serum. These results implicate a role for $\mathrm{Cbl}-\mathrm{b}$ in the resolution of allergic airway inflammation.

Keywords: allergic airway disease, $\mathrm{Cbl}-\mathrm{b}, \mathrm{CD}^{+} \mathbf{T}$ cells, inflammation, tolerance

\section{INTRODUCTION}

Mouse models of allergic airway disease (AAD) are important tools for investigating the underlying mechanisms of allergic asthma in humans. In both mice and humans, $\mathrm{CD} 4^{+} \mathrm{T}$ cells are essential for the initiation of airway inflammation in response to allergen exposure. These $\mathrm{CD} 4^{+} \mathrm{T}$-helper type-2 $\left(\mathrm{T}_{\mathrm{H}} 2\right)$ cells are responsible for providing the proper signals for $\mathrm{B}$ cells to produce immunoglobulin type-E (IgE) antibodies, which are primary mediators of allergic responses through their interactions with receptors on mast cells. Additionally, $\mathrm{T}_{\mathrm{H}} 2 \mathrm{~T}$ cells produce cytokines (e.g., IL-5) that are essential for eosinophil maturation and trafficking to the lung; these cells are hallmarks of allergic inflammation in both mice and humans. Therefore, elucidating the molecular mechanism(s) regulating $\mathrm{CD} 4^{+}$ $\mathrm{T}$ cell activation is an important step toward developing clinical treatments for allergic asthma.

Efficient activation of T cells requires both T-cell receptor (TCR) ligation and costimulation, provided through interactions of T cell surface ligands (e.g., CD28 and ICOS) with corresponding surface receptors on antigen-presenting cells (e.g., B7-1, B7-2, and ICOSL). In the absence of costimulation, TCR ligation results in functional inactivation of T cells, leading to T cell anergy and tolerance induction in vivo $(1,2)$. Therefore, the interactions of numerous costimulatory pathways 
with TCR stimulation are essential for activation of T cells during an inflammatory response.

Negative regulators of costimulatory signal transduction proteins play an important role in $\mathrm{T}$ cell development and activation in vivo. One such regulator is the Casitas B cell lymphoma (Cbl) family of E3 ubiquitin ligases, which play an integral role in mediating TCR signal strength and subsequent survival and activation (3). Two family members, $\mathrm{c}-\mathrm{Cbl}$ and $\mathrm{Cbl}-\mathrm{b}$, regulate TCR signal strength during positive and negative selection in the thymus, and in activation and survival in the periphery (4). Specifically, Cbl-b is important for mediating CD28 signal strength during TCR ligation, through negative control of the signal transduction proteins Vav1, PKC $\theta$, and PLC $\gamma$ (5-8). T cells lacking Cbl-b exhibit a decreased threshold of activation resulting in increased proliferative ability and increased IL-2 production in vitro (9). Cbl-b plays an integral role in governing anergy induction in NK (10) and NK-T cells (11), and inhibition of Cbl-b expression or function in these cells can serve to enhance their anti-tumor activities. Cbl-b also negatively regulates B cell (12) and mast cell function (13). Mice deficient in Cbl-b develop spontaneous autoimmunity at advanced age, characterized by autoantibody production and infiltration of non-lymphoid organs by activated T and B cells (14); also, they have an increased propensity to develop experimentally induced autoimmunity [e.g., experimental autoimmune encephalomyelitis (5)]. Additionally, Cbl-b T cells are resistant to regulatory $\mathrm{T}$ cell $\left(\mathrm{T}_{\mathrm{reg}}\right)$-mediated suppression both in vivo and in vitro, as well as resistant to the immunosuppressive properties of transforming growth factor-beta (TGF- $\beta)(15,16)$.

Ovalbumin (OVA)-induced AAD in mice generates a biphasic response whereby short-term aerosol challenge results in $\mathrm{AAD}$, while long-term aerosol challenge results in a resolution of airway inflammation, referred to as local inhalational tolerance (LIT) (17). The induction of airway inflammation in response to OVA aerosol is critically dependent on $\mathrm{T}_{\mathrm{H}} 2$ cells (18). LIT may be mediated by $\mathrm{T}_{\text {regs }}$, as cells with this phenotype are enriched in local lung compartments at timepoints correlating with the resolution of inflammation (19). As Cbl-b ${ }^{-1-} \mathrm{T}$ cells have been shown to exhibit a decreased activation threshold, and are resistant to Treg-mediated suppression $(15,16)$, these mice provide a unique environment to study the role of $\mathrm{CD} 4^{+} \mathrm{T}$ cell-Treg interactions. A recent study has identified an important role for Cbl-b in mediating allergic inflammation, with Cbl- $\mathrm{b}^{-1-}$ mice on a $B A L B / c$ background exhibiting enhanced $T_{H} 2$ and $T_{H} 9$ responses to OVA-induced AAD (20). This study implicates an important mechanistic role for Cbl-b in governing helper $\mathrm{T}$ cell responses to allergen through regulation of STAT6 and subsequent IL-4 production; however, these studies did not directly address the effect of Cbl-b deficiency on $\mathrm{T}$ cell- $\mathrm{T}_{\text {reg }}$ interactions in the context of allergic airway inflammation and the induction of LIT following chronic allergen exposure. Therefore, the purpose of this study was to determine if Cbl-b deficiency (Cbl- $b^{-/-}$mice) had an effect the development of either the acute (inflammatory) stage or the chronic (resolution) stage of this OVA-induced model, and to determine if the modulated inflammatory response correlated with changes in $\mathrm{T}_{\text {reg }}$ numbers or functions.

\section{MATERIALS AND METHODS}

\section{Animals}

Female C57BL/6 mice, 3-4 months of age and weighing 15-20 g, were purchased from the Jackson Laboratory (Bar Harbor, ME, USA) and housed conventionally in plastic cages with corncob bedding. Cbl- $\mathrm{b}^{-/-}$mice harboring a global homozygous deletion of the Cbl-b gene were bred in the laboratory of Robert Clark, M.D., from breeding pairs originally obtained with permission from Hua Gu, Ph.D. (Columbia University College of Physicians and Surgeons, New York, NY, USA) (5). The animal room was maintained at $22-24^{\circ} \mathrm{C}$ with a daily light/dark cycle. Chow and water were supplied ad libitum. The protocols for animal use were approved by the Animal Care Committee at the University of Connecticut Health Center.

\section{Ovalbumin Exposure Protocol}

As previously described $(17,21)$, mice were immunized with three weekly intraperitoneal (i.p.) injections of a suspension containing $25 \mu \mathrm{g}$ of OVA (grade V, Sigma Chemical, St. Louis, MO, USA) and $2 \mathrm{mg}$ of aluminum hydroxide (alum) in $0.5 \mathrm{ml}$ of $0.9 \%$ sodium chloride in sterile $\mathrm{H}_{2} \mathrm{O}$ (saline). One week after the last injection, the mice were exposed to $1 \%$ aerosolized OVA in $0.9 \%$ sodium chloride in sterile $\mathrm{H}_{2} \mathrm{O}$ (saline) for $1 \mathrm{~h}$ /day for either 7 (AAD) or 42 days (LIT). The aerosols were generated by a BANG nebulizer (CH Technologies, Westwood, NJ, USA) into a 7.61 nose-only inhalation exposure chamber to which individual restraint tubes were attached. Chamber airflow was $6 \mathrm{l} / \mathrm{min}$, and aerosol particle size of OVA was monitored by gravimetric analysis with a Mercer cascade impactor (In-Tox Products, Moriarty, NM, USA). The mass median aerodynamic diameter and geometric SD were 1.4 and $1.6 \mu \mathrm{m}$, respectively. The estimated daily inhaled OVA dose $~ 30-40 \mu \mathrm{g} /$ mouse. Twenty-four hours after the final aerosol exposure, the mice were killed by ketamine/xylazine overdose and subsequent exsanguination.

\section{Bronchoalveolar Lavage/Tissue Analysis}

At sacrifice, local lung compartments such as bronchoalveolar lavage (BAL) fluid, lung tissue, and hilar lymph node (HLN) and systemic compartments such as inguinal lymph node (ILN) and spleens were harvested and processed for the isolation and enumeration of leukocytes. For collection of BAL, lungs were lavaged in situ with five $1 \mathrm{ml}$ aliquots of $0.9 \%$ sodium chloride in sterile $\mathrm{H}_{2} \mathrm{O}$ (saline). The BAL fluid of wild-type and Cbl-b ${ }^{-1-}$ mice at naïve, $\mathrm{AAD}$ and LIT timepoints were centrifuged, the cellular pellet washed, and total viable white blood cells (WBCs) were enumerated using a hemacytometer and vital dye exclusion (nigrosin) as a measure of viability. Cytospin preparations of BAL fluid were stained with May-Grunwald and Giemsa for cell differential analysis. Total eosinophils in BAL fluid were calculated by multiplying the percentages obtained by differential cell analysis by the total WBC count.

For the isolation of cells from lung tissue, mice were perfused with $\mathrm{PBS} / \mathrm{Heparin}$ prior to dissection. Lungs were removed, minced, digested in collagenase $(150 \mathrm{U} / \mathrm{ml})$ (Invitrogen, Carlsbad, CA, USA), and the cellular suspension separated on a Percoll 
(Sigma Chemical, St. Louis, MO, USA) density gradient for the isolation of lymphocytes. Lymph nodes and spleens were harvested and mechanically disrupted into a single-cell suspension. Hypotonic lysis with ammonium chloride lysis buffer $(150 \mathrm{mM}$ $\mathrm{NH}_{4} \mathrm{Cl}, 10 \mathrm{mM} \mathrm{NaHCO}_{3}, 0.1 \mathrm{mM}$ disodium EDTA in sterile $\mathrm{H}_{2} \mathrm{O}$ ) was used to eliminate erythrocytes. For all tissue samples, total WBCs were obtained using a hemocytometer with nigrosin dye exclusion as a measure of viability.

\section{Flow Cytometry and Immunofluorescence}

Cells isolated from the BAL and other tissues were analyzed via flow cytometry using the following monoclonal antibodies: antiCD8a-FITC (53-6.7), anti-CD25-PE (PC61), anti-CD4-PeCy7 (RM4-5), anti-CD3e-PerCP-Cy5.5. (145-2C11), and anti-CD19PerCP-Cy5.5 (1D3) (BD PharMingen, San Diego, CA, USA). Samples were washed in PBS containing $0.2 \%$ bovine serum albumin and $0.1 \% \mathrm{NaN}_{3}$. Aliquots containing $10^{4}-10^{6}$ cells were incubated with $100 \mu \mathrm{l}$ of appropriately diluted antibodies for $30 \mathrm{~min}$ at $4^{\circ} \mathrm{C}$. After staining, the cells were washed with the above PBS solution, and relative fluorescence intensities were determined on a four-decade log scale by flow cytometric analysis using a LSR II (Becton-Dickinson, San Diego, CA, USA). For the identification of $\mathrm{T}_{\text {reg }}$, intracellular staining of Foxp3 protein was used. Briefly, cells stained with the antibodies mentioned previously (i.e., anti-CD3e, anti-CD4, and anti-CD25) were permeabilized using fixation/permeabilization buffer following the manufacturer's protocol, and stained using either anti-Foxp3-FITC (FJK-16s) or anti-Foxp3-APC (FJK16s) with corresponding isotype controls, IgG2a-FITC or -APC (eBioscience, San Diego, CA, USA).

\section{Histology}

After sacrifice, unmanipulated (not subject to BAL) and noninflated lungs from separate animals were removed and fixed with $10 \%$ formalin. Preserved lungs were embedded in paraffin and tissue sections were prepared using a microtome and mounted onto glass slides. Mounted tissue sections were then stained with hematoxylin and eosin for standard evaluation, and periodic acid-Schiff (PAS) for evaluation of mucus production.

\section{IgE ELISA}

Ovalbumin-specific IgE levels were measured by ELISA using isotype-specific capture monoclonal antibodies following a standard protocol (22). Briefly, IgE was captured from diluted serum using Immulon 2 microtiter plates (Dynatech Laboratories, Chantilly, VA, USA) coated with anti-mouse IgE (R35-72; BD PharMingen, San Diego, CA, USA) at $2 \mu \mathrm{g} / \mathrm{ml}$ in $0.1 \mathrm{~mol} / 1$ carbonate, $\mathrm{pH}$ 9.5. Detection was with an OVA-digoxigenin conjugate followed by horseradish peroxidase-conjugated anti-digoxigenin. Plates were developed with the TMB microwell peroxidase substrate system (Kirkegaard and Perry Laboratories, Gaithersburg, MD, USA).

\section{Multiplex Cytokine Analysis}

Concentrations of proinflammmatory cytokines in BAL fluid were measured using a mouse cytokine custom bead assay (Bio-Rad, Hercules, CA, USA) and analyzed using a Luminex Bio-Plex 200 system (Bio-Rad), according to the manufacturer's protocol. Briefly, the 96-well multiplex assay plate was coated with anti-mouse cytokine conjugated beads for the capture of IL-2, IL-4, IL-5, IL-6, IL-10, IL-12p70, IL-13, IFN- $\gamma$, and CCL5 (Eoxtaxin). Plates were rinsed two times with the provided wash buffer, standards and experimental samples were loaded, and the plate was incubated for $30 \mathrm{~min}$ at room temperature with gentle vortex. After three washings, the biotinylated mouse cytokine detection antibody was added for $30 \mathrm{~min}$ at room temperature with gentle vortex. The plates were washed again, and PE-conjugated streptavidin was added for $10 \mathrm{~min}$ at room temperature with gentle vortex. Plates were washed and read using the Luminex Bio-Plex 200 system plate reader according to the manufacturer's instructions. Standard curves were generated by analysis of serially diluted samples of a known cytokine standard provided by the manufacturer. The threshold of detection of each cytokine is $5 \mathrm{pg} / \mathrm{ml}$.

\section{Statistical Analysis}

Analysis of variance (ANOVA) followed by post hoc two-tailed Student's unpaired $t$-tests were used for data analysis. All statistical analysis was performed using either the JMP IN 5.1 statistical software package (SAS Institute, Cary, NC, USA) or the GraphPad Prism 4 software package (GraphPad Software, La Jolla, CA, USA).

\section{RESULTS}

\section{Cbl-b $^{-/-}$Mice Exhibit Increased BAL WBCs and Eosinophils During AAD and LIT}

Prior to sensitization and aerosol challenge, $\mathrm{Cbl}_{-} \mathrm{b}^{-/-}$mice had similar BAL cell composition as wild-type naive controls, consisting primarily of macrophages $(98.3 \pm 0.5 \% \mathrm{WT}$ and $96.1 \pm 0.9 \%$ Cbl- $\left.b^{-/-}\right)$. At AAD, Cbl-b ${ }^{-1-}$ mice developed enhanced airway inflammation compared to wild-type controls, with a significant increase in total BAL leukocytes $(p=0.0016$; Figure 1A) consisting primarily of eosinophils $(83.2 \pm 1.6 \%$ WT and $82.1 \pm 2.2 \%$ Cbl- $\left.\mathrm{b}^{-1-}\right)$. The total number of eosinophils in Cbl-b $\mathrm{b}^{-/-}$BAL fluid at $\mathrm{AAD}$ was increased over twofold as compared to wild-type mice ( $p=0.002$; Figure 1B). At LIT, while both wild-type and Cbl- $\mathrm{b}^{-/-}$mice exhibited significant decreases in total BAL WBCs from their respective AAD levels $(p<0.05$ for LIT vs. AAD) (Figure 1A), there remained a significant increase in total WBCs (over 4-fold; $p=0.046$; Figure 1A) and eosinophils (over 12-fold; $p=0.030$; Figures $1 \mathrm{~B}, \mathrm{C}$ ) in the BAL of Cbl- $\mathrm{b}^{-/-}$mice as compared to wild-type mice.

\section{$\mathrm{Cbl}^{-b^{-/}}$Mice Demonstrated Histological Evidence of Increased Lung Inflammation and Mucus Production During AAD and LIT}

Cbl-b $\mathrm{b}^{-/-}$mice have an increased propensity to develop both spontaneous autoimmunity and experimentally induced autoimmune diseases $(5,14)$. To ensure that the lung histological observations seen in $\mathrm{Cbl-b}^{-/-}$mice were not due to pre-existing airway inflammation prior to sensitization and aerosol challenge, lungs from 

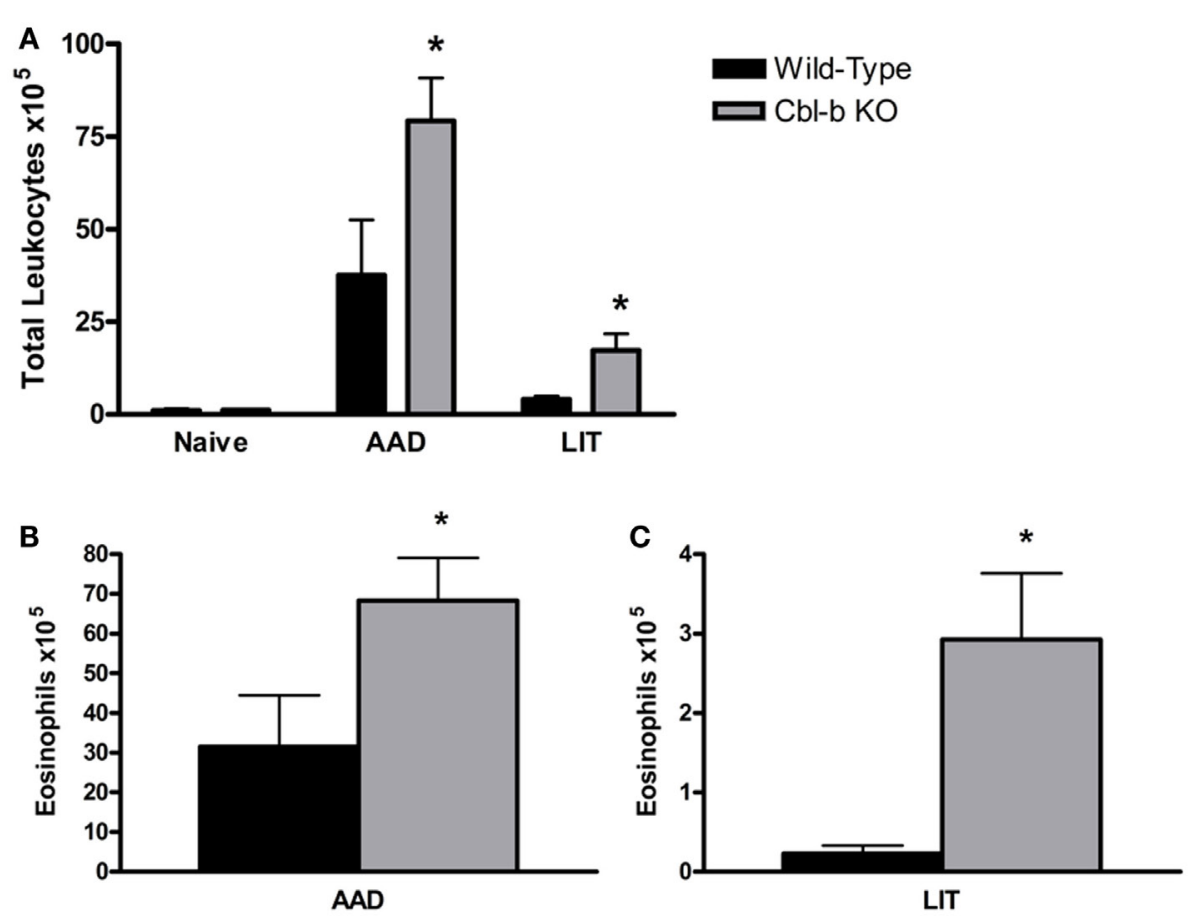

FIGURE 1 | Total white blood cells and eosinophils are increased in the BAL of Cbl-b ${ }^{-/-}$mice at AAD and LIT. (A) Total white blood cells (WBCs) in BAL fluid were enumerated using a hemacytometer and nigrosin stain for viability. (B,C) Cytokine preparations of BAL fluid from AAD (B) and LIT (C) mice were stained with May-Grunwald and Giemsa for cell differential analysis. Total eosinophils in BAL fluid were calculated by multiplying the percentages obtained by differential cell analysis by the total WBC count. Data represent the mean + SEM of 7-9 mice per group. ${ }^{*} p<0.05$ vs. respective AAD or LIT wild-type mice.

age-matched and older (18 weeks) Cbl-b ${ }^{-1-}$ mice were analyzed for airway inflammation. Naïve wild-type (Figure 2A), naïve agedmatched Cbl-b ${ }^{-1-}$ (Figure 2B), and 18-week-old Cbl-b ${ }^{-/-}$lungs (data not shown) were comparable with little to no evidence of airway inflammation prior to sensitization and aerosol challenge.

At $\mathrm{AAD}$, qualitative analysis of lungs from $\mathrm{Cbl}_{-\mathrm{b}^{-/}}$mice showed increased perivascular and peribronchial inflammation (Figure 2D) as compared to wild-type mice (Figure 2C). Similar increases in mucus production (Figure 2D - insert) were seen for Cbl-b ${ }^{-/-}$mice as compared to wild-type mice (Figure 2C - insert), with significant mucus plugging apparent in the bronchial airways. This increase in lung inflammation was striking at LIT, with significant perivascular and peribronchial inflammation persisting in $\mathrm{Cbl-b^{-/ }}$ mice (Figure 2F) as compared to the resolution of inflammation in wild-type mice (Figure 2E) in response to long-term aerosol challenge. Along with increased inflammation, Cbl- $\mathrm{b}^{-/-}$mice also showed evidence of mucus production in the airways at LIT (Figure 2F - insert), whereas wild-type mice had airways that were clear of mucus production (Figure 2E insert).

\section{Exacerbation of Inflammation in $\mathrm{Cbl}-\mathrm{b}^{-/-}$ Mice Resulted in Modulation of the Lymphocyte Populations in the HLN at LIT but Not AAD}

As Cbl-b mice exhibited increased airway inflammation and eosinophilia in response to aerosol challenge, we sought to determine if the total number and/or frequency of lymphocyte subsets in local (HLN) and systemic (ILN) tissues were affected as well. No significant differences were seen in percentages or total numbers of T or B cell subsets analyzed in the wild-type or Cbl- $b^{-1-}$ mice at naïve or sensitized timepoints (data not shown). At AAD, a similar pattern was observed, with no significant differences in $\mathrm{T}$ or $\mathrm{B}$ cell subsets in either local lung or systemic tissues, either in regards to cell percentages (data not shown) or total cells (Table 1A). In a similar manner, no significant differences were found between percentages or total numbers of $\mathrm{CD}^{+}$, $\mathrm{CD}^{+}$, or $\mathrm{CD} 19^{+}$lymphocytes in the BAL, ILN, and spleen at LIT (Table 1B). However, in the HLN at LIT, Cbl-b ${ }^{-1-}$ mice had increased numbers of all lymphocytes analyzed as compared to wild-type mice, indicative of an increase in total cellularity of the node. This increase was not due to changes in the distribution of lymphocyte subsets in the HLN, as percentages of $\mathrm{CD}^{+}, \mathrm{CD} 4^{+}$, and $\mathrm{CD} 19^{+}$cells were equivalent (data not shown).

During the progression from AAD to LIT in this OVA model, the ratio of $\mathrm{T}$ cell subsets in the BAL of wild-type mice shows a progression from a $\mathrm{CD}^{+}$environment $(\sim 2: 1)$ to a normalized CD4:CD8 environment ( 1:1) (21). In Cbl-b $\mathrm{b}^{-/-}$mice, the ratio of total CD4:CD8 $\mathrm{T}$ cells in the BAL was skewed toward $\mathrm{CD}^{+} \mathrm{T}$ cells $(\sim 1.5)$ in comparison to the ratio in wild-type mice ( 2.2). However, this difference was not apparent for total numbers of $\mathrm{CD}^{+}$or $\mathrm{CD}^{+} \mathrm{T}$ cells in the BAL when compared between wild-type and $\mathrm{Cbl-b^{-/ }}$ mice. At LIT, the BAL of $\mathrm{Cbl}^{-\mathrm{b}^{-1-}}$ mice showed a skewed CD4:CD8 T cell ratio $(\sim 0.8)$ 


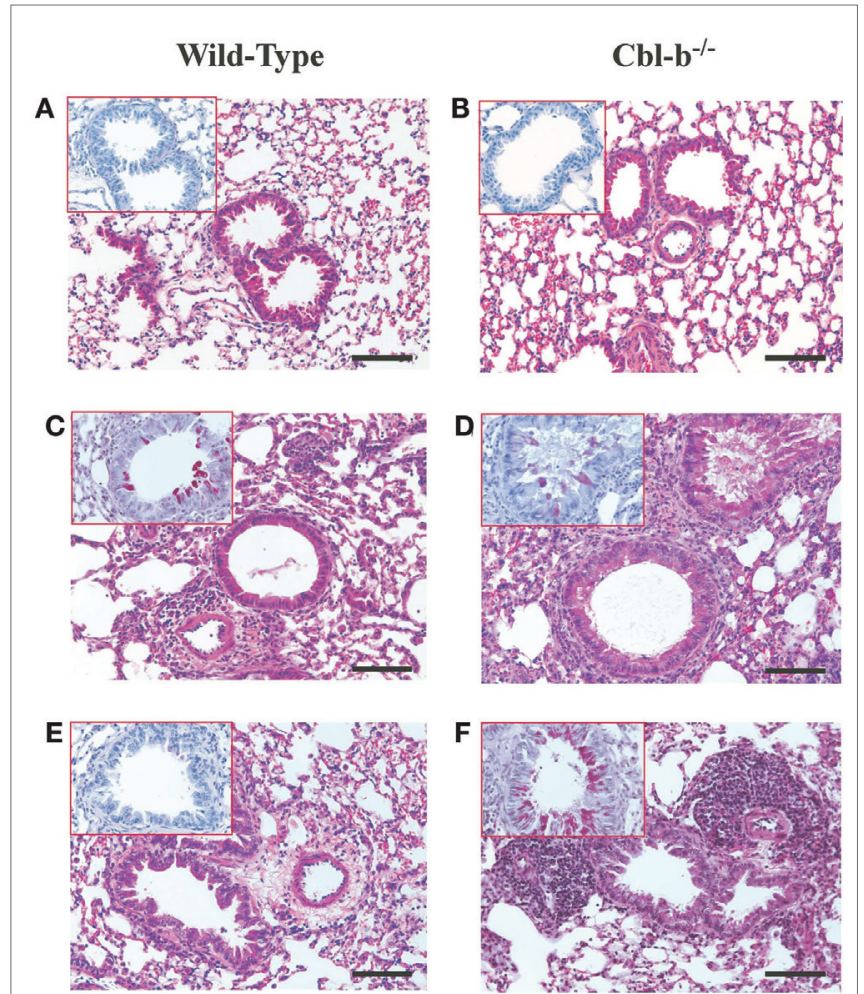

FIGURE 2 | Lung histology from wild-type and Cbl-b mice. Formalinfixed lungs from wild-type or $\mathrm{Cbl}^{-b^{-/}}$mice at naïve (A,B), AAD (C,D) or LIT (E,F) were stained with Hematoxin and Eosin (H\&E) for analysis of tissue inflammation, and periodic acid-Schiff (PAS) (inserts) for the identification of mucus production. All sections at 20x magnification. Scale bar $=100 \mu \mathrm{m}$.

as compared to wild-type mice $(\sim 1.5)$, which was largely due to a statistically significant increase in percentages of $\mathrm{CD} 8^{+} \mathrm{T}$ cells (of lymphocytes, $10.3 \pm 2.8 \%$ for wild-type vs. $23.6 \pm 3.0 \%$ for Cbl-b $\left.{ }^{-/-}, p=0.019\right)$. While all lymphocyte subsets analyzed were increased in terms of total number in the Cbl-b ${ }^{-/-} \mathrm{BAL}$, these differences were not statistically significant, primarily due to increased variation in total numbers of lymphocytes in the $\mathrm{Cbl}^{-1-}$ mice.

\section{Cbl-b Deficiency Did Not Result in Increased OVA-Specific IgE Production in} Serum

A standard outcome of this OVA-induced model of AAD is the production of OVA-specific IgE in the serum, which is a hallmark of $\mathrm{T}_{\mathrm{H}} 2$ allergic responses in both mice and humans. Serum levels of OVA-IgE in naïve or sensitized wild-type and $\mathrm{Cbl-b}^{-/-}$mice were minimal and showed no significant differences between strains (Figure 3). At AAD, both wild-type and Cbl-b $\mathrm{b}^{-/-}$exhibited elevated serum OVA-IgE levels; however, there were no significant differences observed in OVA-IgE concentrations between mouse strains ( $p=0.38$; Figure 3). Similarly, OVA-IgE levels remained elevated in both mouse strains at LIT; however, there were no significant differences observed between wild-type and Cbl- $b^{-/-}$mice $(p=0.20$; Figure 3$)$.

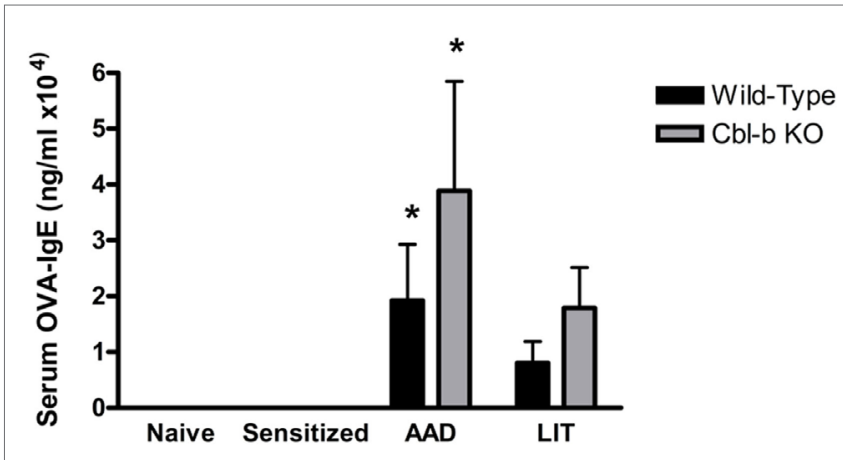

FIGURE 3 | Systemic serum OVA-IgE levels in wild-type and $\mathrm{Cbl-b}$ mice are increased at AAD. Serum from wild-type or Cbl-b mice was isolated at the indicated timepoints and analyzed via OVA-specific IgE ELISA. Data represent the mean \pm SEM of $6-8$ mice per group. ${ }^{*} p<0.05$ vs. Naïve/ Sensitized levels.

TABLE 1 | Lymphocyte numbers in local and systemic tissues at AAD and LIT.

\begin{tabular}{|c|c|c|c|c|}
\hline & & $\mathrm{CD}^{+}$ & $\mathrm{CD4}^{+}$ & CD19+ \\
\hline \multicolumn{5}{|l|}{ (A) AAD } \\
\hline \multirow[t]{2}{*}{$\mathrm{BAL}$} & Wild-type & $6.2 \pm 2$ & $13.8 \pm 5$ & $11.7 \pm 9$ \\
\hline & Cbl-b-1- & $15.8 \pm 4$ & $23.9 \pm 6$ & $10.1 \pm 4$ \\
\hline \multirow[t]{2}{*}{ HLN } & Wild-type & $61.8 \pm 25$ & $79.9 \pm 34$ & $159.3 \pm 128$ \\
\hline & $\mathrm{Cbl}_{-\mathrm{b}^{-/-}}$ & $143.3 \pm 43$ & $160.2 \pm 48$ & $424.7 \pm 163$ \\
\hline \multirow[t]{2}{*}{ ILN } & Wild-type & $24.2 \pm 9$ & $27.9 \pm 10$ & $20.4 \pm 6$ \\
\hline & Cbl-b-1- & $25.8 \pm 7$ & $23.9 \pm 6$ & $21.6 \pm 7$ \\
\hline \multirow[t]{2}{*}{ Spleen } & Wild-type & $171.7 \pm 28$ & $303.2 \pm 65$ & $169.5 \pm 34$ \\
\hline & $\mathrm{Cbl}_{-\mathrm{b}^{-/-}}$ & $172.5 \pm 39$ & $326.3 \pm 68$ & $148.3 \pm 20$ \\
\hline \multicolumn{5}{|l|}{ (B) LIT } \\
\hline \multirow[t]{2}{*}{ BAL } & Wild-type & $0.9 \pm 0.2$ & $1.4 \pm 0.2$ & $0.5 \pm 0.04$ \\
\hline & Cbl- $\mathrm{b}^{-/-}$ & $9.8 \pm 5$ & $7.6 \pm 4$ & $3.3 \pm 1$ \\
\hline \multirow[t]{2}{*}{ HLN } & Wild-type & $116.7 \pm 37$ & $111.4 \pm 28$ & $64.6 \pm 1$ \\
\hline & $\mathrm{Cbl}_{-\mathrm{b}^{-/-}}$ & $291.1 \pm 65^{\star}$ & $259.9 \pm 53^{\star}$ & $265.0 \pm 43^{*}$ \\
\hline \multirow[t]{2}{*}{ ILN } & Wild-type & $41.8 \pm 10$ & $44.8 \pm 10$ & $7.1 \pm 1$ \\
\hline & Cbl-b-1- & $21.1 \pm 7$ & $19.7 \pm 6$ & $3.2 \pm 2$ \\
\hline \multirow[t]{2}{*}{ Spleen } & Wild-type & $142.3 \pm 53$ & $230.3 \pm 74$ & $159.6 \pm 74$ \\
\hline & Cbl-b-'-- & $171.3 \pm 38$ & $232.3 \pm 48$ & $310.3 \pm 125$ \\
\hline
\end{tabular}

Single-cell suspensions of the indicated tissues and tissue compartments were analyzed via flow cytometry for the presence of $C D 8^{+}, C D 4^{+}$, and $C D 19^{+}$lymphocytes. Total numbers (cells $\left.\times 10^{4}\right)$ were obtained as indicated in the Section "Materials and Methods." $n=5-8$ mice per group. ${ }^{*} p<0.05$ vs. wild-type.

\section{$\mathrm{Cbl-b}^{-/-}$Mice Exhibited Increased Levels of Proinflammatory Cytokines and Chemokines in the BAL During AAD and LIT}

As the increased airway inflammation in Cbl- $b^{-/-}$mice during $\mathrm{AAD}$ and LIT did not correlate with modulations in lymphocyte populations in the BAL (Table 1) or increases in systemic OVAspecific IgE (Figure 3), we sought to determine if increases in proinflammatory cytokines in the local lung environment correlated with the exacerbation of inflammation in $\mathrm{Cbl}_{-\mathrm{b}^{-/}}$mice. BAL proteins from both wild-type and $\mathrm{Cbl}_{-} \mathrm{b}^{-/-}$mice at the 
indicated timepoints were analyzed via multiplex bead assay for the presence of numerous proinflammatory cytokines, along with the T cell chemotactic factor CCL5 (RANTES) (Figure 4).

No significant differences were observed between wild-type and $\mathrm{Cbl}_{-} \mathrm{b}^{-/-}$mice at the indicated timepoints for levels of IL-2 (Figure 4A), IL-4 (Figure 4B), IL-10 (Figure 4E), or IL-12p70 (Figure 4F). However, Cbl- $\mathrm{b}^{-1-}$ mice had increased levels of the $\mathrm{T}_{\mathrm{H}} 2$ cytokines IL-5 (Figure 4C) and IL-13 (Figure 4G), along with the proinflammatory cytokine IL-6 (Figure 4D) in the BAL at $\mathrm{AAD}$ as compared to wild-type. At LIT, Cbl-b ${ }^{-1-}$ mice had increased levels of both IL-5 (Figure 4C) and CCL5 (Figure 4H) in the BAL as compared to wild-type, while levels of IL-6 and IL-13 returned to levels comparable to wild-type. In addition, no significant differences were observed in IFN $\gamma$ levels between wildtype and Cbl- $\mathrm{b}^{-/-}$mice, as IFN $\gamma$ was not detected in the BAL at any timepoint of the model in either mouse strain (data not shown).

\section{CD4 $^{+}$CD25 $^{+}$Foxp3 $^{-}$Activated T Cells Are Increased in the BAL of $\mathrm{Cbl}_{-\mathrm{b}^{-/}}$Mice at AAD}

To further characterize the $\mathrm{CD} 4^{+} \mathrm{T}$ cell response in local lung vs. systemic tissues during AAD and LIT, CD4 ${ }^{+} \mathrm{T}$ cells were analyzed for expression of the activation marker CD25 and the regulatory $\mathrm{T}$ cell-specific transcription factor Foxp3. As with the previous lymphocyte characterization, no significant differences were found between wild-type and Cbl- $\mathrm{b}^{-/-}$mice for percentages of $\mathrm{CD}^{+} \mathrm{CD}^{+} 5^{+}$Foxp3 $^{-}$and $\mathrm{CD} 4^{+} \mathrm{CD} 25^{+}$Foxp $^{+}$in systemic compartments at all timepoints (data not shown). However, Cbl- $\mathrm{b}^{-/-}$mice did exhibit an increase in the Foxp3 $3^{-}$population in the BAL during $\mathrm{AAD}$, in terms of percentage of the total CD4 ${ }^{+}$ population $(8.64 \pm 0.8 \%$ for wild-type vs. $12.6 \pm 0.9 \%$ for Cbl$\mathrm{b}^{-/-}, n=5$ for each group, $p<0.01$ ) (Figure 5A). When these values are expressed as a ratio, the differences in cell composition during AAD become apparent, with an increase in Foxp3 ${ }^{-}$in Cbl- $\mathrm{b}^{-/-}$mice (Figure 4B). At LIT, this difference was no longer apparent, as percentages of Foxp $3^{-}$and Foxp $3^{+}$were equivalent between wild-type and Cbl- $b^{-1-}$ mice $(4.90 \pm 0.9 \%$ for wild-type vs. $5.86 \pm 0.8 \%$ for Cbl-b, $n=5$ for each group) (Figure $5 \mathrm{~B}$ ).

\section{DISCUSSION}

The role of Cbl-b in the regulation of peripheral $\mathrm{T}$ cell responses is well documented; however, its role in mediating $\mathrm{T}_{\mathrm{H}} 2$-type allergic responses remains elusive. The results of these studies indicate that Cbl-b plays an integral role in regulating the intensity of an allergic airway response in mice, as $\mathrm{Cbl-b^{-/ }}$ mice exhibit increased inflammation during acute and chronic stages of an OVA-induced AAD model. This exacerbation does not appear to be due to the inherent autoimmune phenotype of $\mathrm{Cbl}^{-b^{-/}}$mice (9), since age-matched (i.e., 18-week) naive $\mathrm{Cbl}^{-\mathrm{b}^{-1-}}$ mice did not develop airway inflammation. These results indicate that Cbl-b deficiency can influence the severity of AAD through the dysregulation of $\mathrm{T}$ cell responses.

Long-term aerosol exposure in OVA-sensitized mice results in the resolution of AAD, characterized by a reversal of eosinophilia and mucus secretion in the airways $(17,21)$. Interestingly, the

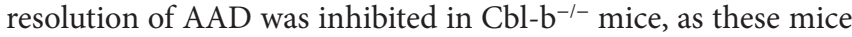
exhibited persistent eosinophilia and mucus secretion in the airways at the chronic stage as compared to wild-type controls. Previous reports have indicated that the resolution of AAD in wild-type mice is dependent on continuous aerosol exposure (17). These results suggest that the inability of $\mathrm{Cbl}_{-} \mathrm{b}^{-/-}$mice to resolve AAD in response to long-term continuous aerosol exposure may be due to its inability to mount a $\mathrm{T}_{\text {reg }}$-mediated local inhalational tolerant state, perhaps via the dysfunctional nature of $\mathrm{T}_{\text {reg }}$ interactions in these mice.

Along with histological evidence of increased airway inflammation, Cbl-b $\mathrm{b}^{-/-}$mice exhibited increased levels of the proinflammatory cytokines IL-5, IL-6, and IL-13 in the BAL at AAD. Additionally, levels of the $\mathrm{T}_{\mathrm{H}} 2$ cytokine IL-5 and the $\mathrm{T}$ cell chemokine CCL5 were increased at LIT above wild-type levels, indicating a role for these immune modulating signaling proteins in the exacerbation of inflammation during prolonged aerosol exposure in Cbl-b ${ }^{-1-}$ mice. IL-5 and IL-13 are $\mathrm{T}_{\mathrm{H}} 2$ cytokines associated with the development of airway inflammation in mice (23) and humans $(24,25)$; the observed increase in these proinflammatory cytokines in $\mathrm{Cbl}^{-\mathrm{b}^{-/-}}$mice is suggestive of exacerbated $\mathrm{T}_{\mathrm{H}} 2$ cell responses to aerosol challenge during acute inflammation. While the role of IL-6 in allergic inflammation is less clear, it is a potent inflammatory cytokine, and has been shown to play a role in fungal-induced asthma (26). Additionally, IL- 6 has been shown to act as a negative regulatory of $\mathrm{T}_{\text {reg }}$ function $(27,28)$, suggesting that the increase in IL-6 at $\mathrm{AAD}$ in $\mathrm{Cbl-b^{-/- }}$ may be evidence of "resistance to regulation" during acute inflammation through IL-6 mediated inhibition of $\mathrm{T}_{\text {reg }}$ suppression. At LIT, levels of IL-5 were significantly increased compared to wild-type, which may provide a mechanism for the increased eosinophils in the BAL of Cbl- $\mathrm{b}^{-/-}$mice at LIT, as IL-5 is a potent chemoattractant and activation factor for eosinophils $(29,30)$. Interestingly, levels of CCL5 in the BAL of Cbl-b ${ }^{-1-}$ mice were increased above wild-type levels only at LIT, suggesting that increased $\mathrm{T}$ cell chemokine expression in $\mathrm{Cbl}-\mathrm{b}^{-/-}$mice may play a role at exacerbating inflammation at LIT.

Cbl-b ${ }^{-/-}$effector T cells ( $\mathrm{T}_{\text {eff }}$ ) have been shown to be "resistant to regulation," in that they are unresponsive to the suppressive effects of either $\mathrm{T}_{\text {reg }}$ or the immunosuppressive cytokine TGF- $\beta$ both in vitro and in vivo $(15,16)$. This deficiency in regulation is not due to intrinsic defects in Cbl- $\mathrm{b}^{-/-} \mathrm{T}_{\mathrm{reg}}$, as these cells are capable of suppressing wild-type $\mathrm{T}_{\text {eff }}$ proliferation in vitro (15). However, the ability of naïve Cbl- $\mathrm{b}^{-1-} \mathrm{T}_{\text {eff }}$ to respond to $\mathrm{T}_{\mathrm{reg}}$ in vivo and in vitro is severely impaired (15), suggesting that "resistance to regulation" may be due to defects in the cross-talk necessary between $\mathrm{T}_{\text {eff }}$ and $\mathrm{T}_{\text {reg }}$ for the suppression of inflammation. $\mathrm{T}_{\text {reg }}$ are believed to play an important role in the development and/or maintenance of LIT, as Foxp $3^{+} \mathrm{T}$ cells are increased in local lung compartments in response to long-term aerosol challenge (19). Therefore, increased inflammation in $\mathrm{Cbl}^{-\mathrm{b}^{-1-}}$ mice may be due to defects in regulation of activated $\mathrm{T}$ cell-mediated inflammation by $\mathrm{T}_{\text {reg }}$ during the progression from AAD to LIT. Importantly, the definition of activated $\mathrm{T}$ cell in this model system does not address the issue of antigen specificity. Further studies are required to determine if the increase in inflammation observed in Cbl- $b^{-/-}$are due to an expansion of OVA-specific T cell subsets, 

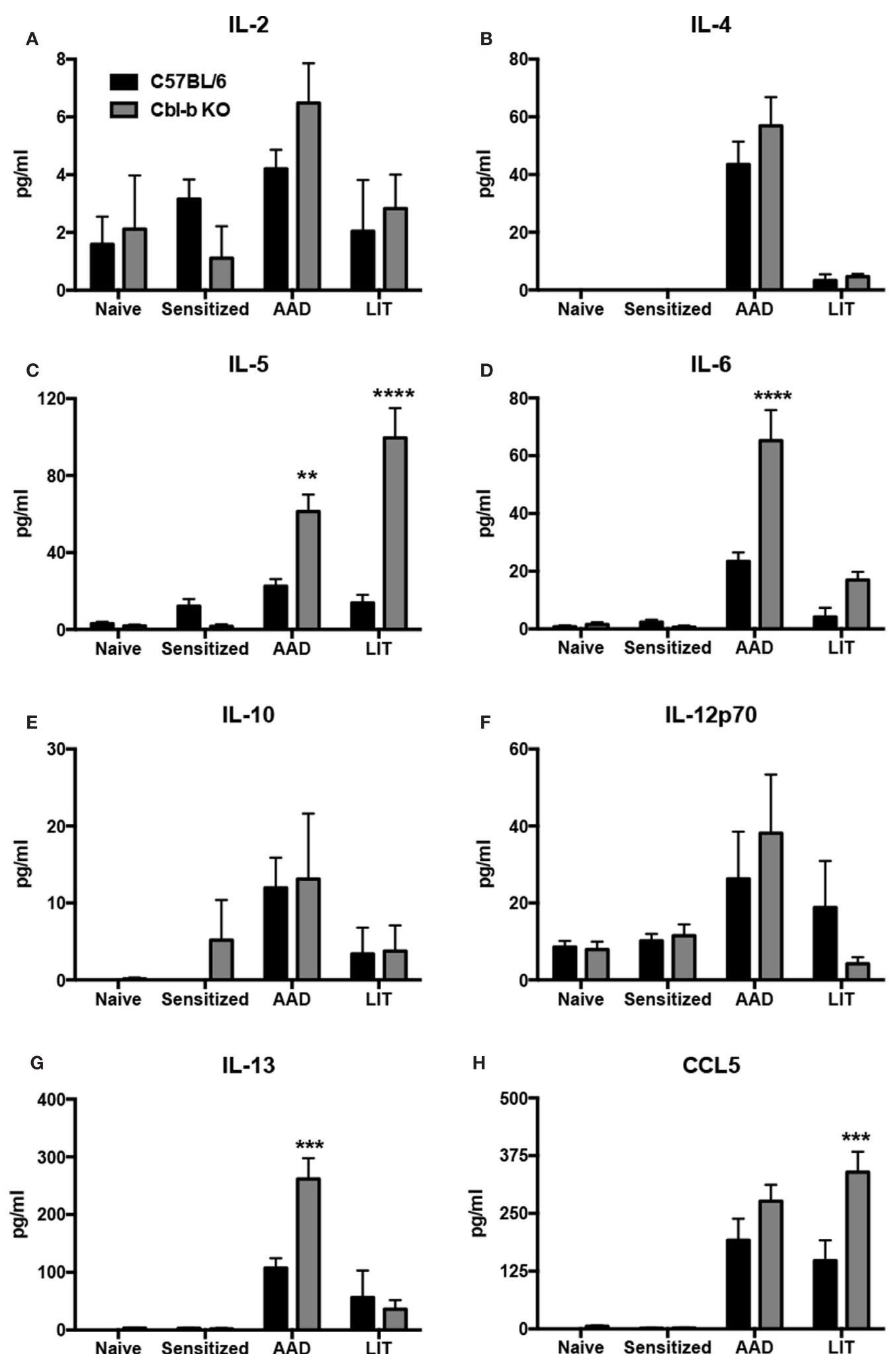

FIGURE 4 | Proinflammatory cytokines and chemokines were increased in the BAL of Cbl-b ${ }^{-1-}$ mice at AAD and LIT. Concentrated BAL samples from wild-type (C57BL/6) and Cbl-b-/- mice at the indicated timepoints were analyzed via multiplex bead assay for the presence of IL-2 (A), -4 (B), -5 (C), -6 (D), -10 (E), $-12 \mathrm{p} 70 \mathbf{( F )}$, and $-13 \mathbf{( G )}$ along with the T cell chemotactic factor CCL5 (H). Data represent the mean \pm SEM of $4-6$ mice per group. ${ }^{* \star} p<0.01$, ${ }^{\star \star \star} p<0.001$, ${ }^{\star \star \star \star} p<0.0001$ vs. wild-type. 


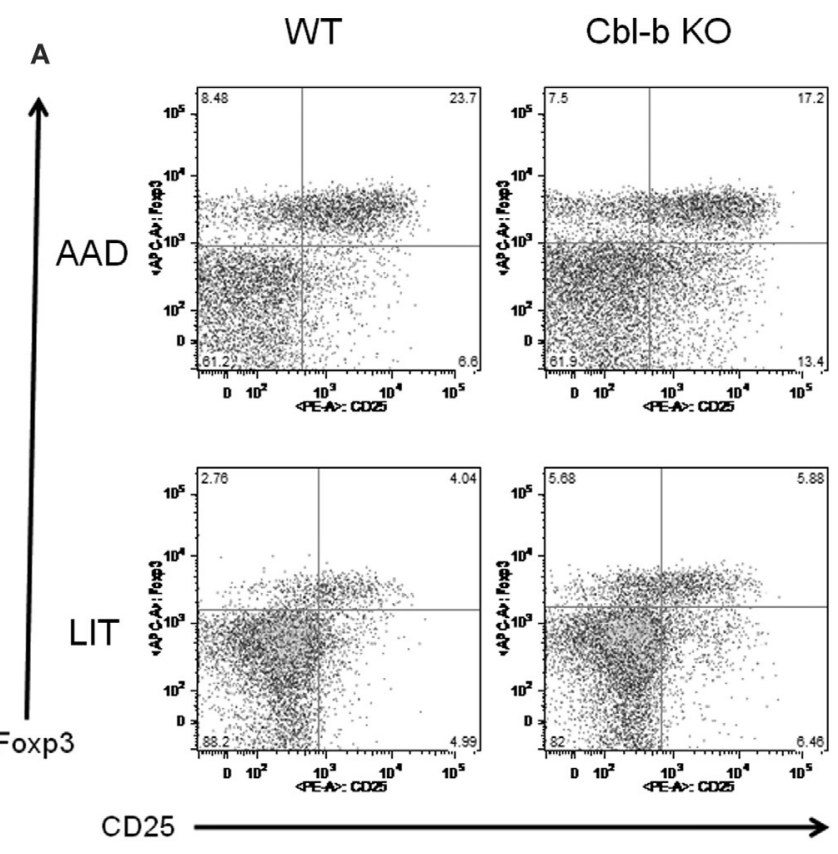

B

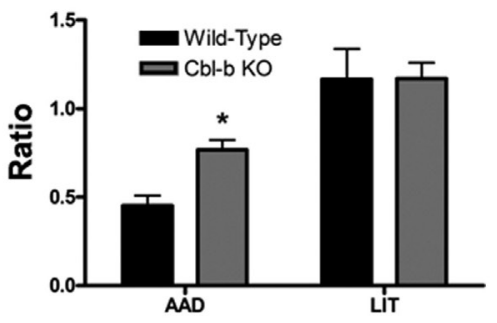

FIGURE 5 | Percentage of CD4 ${ }^{+}$CD25 $^{+}$Foxp3- $\mathbf{T}$ cells are increased in BAL of Cbl-b ${ }^{-/}$mice during AAD. (A) Representative flow cytometric analysis of BAL fluid from wild-type and $\mathrm{Cbl-b^{-/ }}$ mice at AAD and LIT. Samples were gated on $C D 3^{+} C D 4^{+} T$ cells. (B) Ratio of BAL T cells at AAD and LIT in wild-type and $\mathrm{Cbl}-\mathrm{b}^{-/-}$mice. Ratios were obtained by dividing the percentage of $\mathrm{CD} 4^{+} \mathrm{CD} 25^{+}$Foxp3 ${ }^{-} \mathrm{T}$ cells by the percentage of $\mathrm{CD} 4^{+} \mathrm{CD}_{2} 5^{+}$Foxp3 $3^{+} \mathrm{T}$ cells. Data represent the mean \pm SEM of 5 mice per group. ${ }^{*} p<0.05$ vs. wild-type.

enhanced activation of an equivalent population of OVA-specific $\mathrm{T}$ cells, or some combination of both phenomena.

Cbl-b plays an important role in $\mathrm{T}$ cell activation through its interaction with signal transduction factors downstream of CD28. Additionally, Cbl-b plays a role in regulating $\mathrm{T}_{\text {eff }}$ function after antigen-induced activation through involvement with cellintrinsic and cell-to-cell regulatory pathways. In terms of cellintrinsic pathways, Cbl-b has been shown to play an important role in anergy induction in response to tolerizing signals (31, 32). For example, $\mathrm{T}$ cells from $\mathrm{Cbl}-\mathrm{b}^{-/-}$mice exhibit an inability to develop anergy in response to calcium ionophore treatment in vitro, and in vivo antigen challenge of in vitro anergized $\mathrm{Cbl}^{-\mathrm{b}^{-1}} \mathrm{~T}$ cells with cognate antigen results in $\mathrm{T}$ cell-mediated lethality in recipient mice (33). Calcium-mediated anergy induction proceeding through calcineurin has also been shown to rely on Cbl-b, along with other E3 ubiquitin ligases, as expression of Cbl-b was increased in sustained calcium flux-mediated anergic T cells (7). Based on these findings, it is possible that the increased airway inflammation in $\mathrm{Cbl-b^{-/- }}$ mice may be due to a deficiency in anergy induction in activated T cells, especially in terms of chronic antigen exposure at LIT.

Cbl-b $\mathrm{b}^{-1-}$ mice in our model exhibited a modulation in the $\mathrm{CD} 4^{+}$ $\mathrm{CD} 25^{+}$Foxp $3^{-} \mathrm{T}$ cell population during AAD as these cells were increased as a percentage of the total $\mathrm{CD} 4^{+} \mathrm{T}$ cell population in the BAL as compared to wild-type BAL. This increase in Foxp3 ${ }^{-} \mathrm{T}$ cells in local lung compartments during AAD may be influencing the increase in airway inflammation seen in $\mathrm{Cbl}_{-\mathrm{b}^{-/}}$mice. At LIT, wild-type and $\mathrm{Cbl-b^{-/- }}$ mice had equivalent frequencies of Foxp $3^{-}$and Foxp $3^{+} \mathrm{T}$ cells in the BAL, which appears in contrast to the increased airway inflammation seen at LIT in Cbl-b ${ }^{-1-}$ mice. However, the inability to resolve airway inflammation in Cbl-b ${ }^{-/-}$mice at LIT may be due to the "resistant to regulation" phenotype of Cbl- $b^{-1-} \mathrm{T}$ cells and not to enhanced Foxp3 $3^{-} \mathrm{T}$ cell populations as seen at $\mathrm{AAD}$. These results suggest that separate mechanisms may control the severity of inflammation at AAD and LIT, with both involving Cbl-b. For example, the inability of Cbl- $b^{-1-} \mathrm{T}$ cells to be regulated by Foxp $3^{+} \mathrm{T}_{\text {reg }}$ may play a role in the expanded Foxp $3^{-}$activated $\mathrm{T}$ cell pool seen at AAD, while a combination of resistance to "(extrinsic) regulation" by $\mathrm{T}_{\mathrm{reg}}$ and "(intrinsic) regulation" through anergy induction may result in the maintenance of airway inflammation at LIT. Further studies are required to assess the functionality of $\mathrm{T}$ cell subpopulations in the BAL at AAD and LIT in Cbl-b mice, along with the role of TGF- $\beta$, which has been shown to be induced as a result of OVA aerosol challenge in this model (17).

For the most part, the effect of Cbl-b deficiency on the severity of inflammation during AAD and LIT did not result in modulations in lymphocyte populations. For example, Cbl- $b^{-1-}$ mice did not exhibit increases in $\mathrm{CD}^{+}$or $\mathrm{CD}^{+} \mathrm{T}$ cells, or $\mathrm{CD} 19^{+} \mathrm{B}$ cells, in local lung or systemic compartments during AAD and LIT, suggesting that the exacerbation of inflammation in Cbl- $b^{-/}$mice was not due to increases in numbers of effector lymphocytes. Interestingly, a general increase of total numbers of all lymphocytes analyzed was observed in the HLN of Cbl-b ${ }^{-/-}$mice at LIT. Previous studies have indicated that $\mathrm{T}$ cells lacking Cbl-b exhibit a hyperproliferative phenotype in vitro $(5,9)$, suggesting a possible cause for this observed expansion of $\mathrm{T}$ cells in this in vivo model. Of additional interest is the skewing of the $\mathrm{T}$ cell response in $\mathrm{Cbl}_{-} \mathrm{b}^{-/-}$mice 
toward $\mathrm{CD}^{+}{ }^{+} \mathrm{T}$ cells, especially in the BAL. Cbl-b ${ }^{-/-}$mice exhibited a decreased CD4:CD8 T cell ratio at both AAD and LIT as compared to wild-type mice, which is unexpected due to the $\mathrm{T}_{\mathrm{H}} 2$-type nature of the OVA-induced AAD response. Little is known about the role of Cbl-b in T-helper polarization; however, Cbl-b has been indicated in TCR-mediated activation-induced cell death (AICD) in $\mathrm{T}_{\mathrm{H}} 1$ cells (34), and has been shown to play a role in skewing thymocyte development toward $\mathrm{CD}^{+} \mathrm{T}$ cells in $\mathrm{c}-\mathrm{Cbl} / \mathrm{Cbl}-\mathrm{b}$ dual $^{-/-}$mice (35). These studies provide evidence that dysregulated $\mathrm{T}_{\mathrm{H}} 1$ responses or $\mathrm{CD} 8^{+} \mathrm{T}$ cell development in $\mathrm{Cbl}_{-} \mathrm{b}^{-/-}$mice could result in the increase in $\mathrm{CD}^{+} \mathrm{T}$ cells at $\mathrm{AAD}$ and LIT.

In addition, Cbl-b has been shown to play an important role in negatively regulating B cell receptor (36) and CD40 signal strength (37), suggesting a similar mechanism governing the expansion of $\mathrm{B}$ cells in the HLN of Cbl- $\mathrm{b}^{-/-}$mice during LIT. However, conflicting reports suggest that Cbl-b acts as a positive regulator of $\mathrm{B}$ cell activation through interactions with TRANCE receptor (38) and Erk (39) with downstream effects on calcium mobilization and the signal transduction proteins Akt and Lyn. While the expansion of B cells in the HLN during LIT appears to correlate with increased inflammation in the lungs of Cbl- $b^{-1-}$ mice, it is not cell-specific, as all lymphocyte subsets analyzed were increased in the HLN of Cbl- $b^{-1-}$ mice at LIT. Similarly, while serum IgE levels were slightly elevated in Cbl-b $\mathrm{b}^{-/-}$mice as compared to wild-type controls, they were not statistically significant. This observation may be explained by the observed patterns of cytokine expression observed in this animal model. For example, despite elevated production of specific $\mathrm{T}_{\mathrm{H}} 2$ cytokines in Cbl-b $\mathrm{b}^{-/-}$mice, such as IL-5 and IL-13, there was no significant elevation in IL-4 production observed. As IL-4 is the primary $\mathrm{T}_{\mathrm{H}} 2$ cytokine responsible for IgE class-switching (40), the equivalent production of $\mathrm{IgE}$ in $\mathrm{Cbl}^{-\mathrm{b}^{-/}}$mice during AAD and LIT may be due to the equivalent IL-4 production observed concurrently at both timepoints. Regardless, these findings suggest a possible role for $\mathrm{B}$ cell dysregulation in Cbl- $\mathrm{b}^{-/-}$mice in this model, albeit one that needs to be further elucidated.

Previous work indicates that OVA-induced allergic airway inflammation in mice can be induced in B cell deficient mice (41, 42). However, recent studies have indicated that Cbl-b plays an important role in regulating mast cell activation (43) and subsequent cytokine production (44) by IgE-activated mast cells, which are critical mediators in allergic lung inflammation in both mice

\section{REFERENCES}

1. Appleman LJ, Boussiotis VA. T cell anergy and costimulation. Immunol Rev (2003) 192:161-80. doi:10.1034/j.1600-065X.2003.00009.x

2. Schwartz RH. T cell anergy. Annu Rev Immunol (2003) 21:305-34. doi:10.1146/ annurev.immunol.21.120601.141110

3. Liu YC, Gu H. Cbl and Cbl-b in T-cell regulation. Trends Immunol (2002) 23:140-3. doi:10.1016/S1471-4906(01)02157-3

4. Thien CB, Langdon WY. c-Cbl and Cbl-b ubiquitin ligases: substrate diversity and the negative regulation of signalling responses. Biochem J (2005) 391:153-66. doi:10.1042/BJ20050892

5. Chiang YJ, Kole HK, Brown K, Naramura M, Fukuhara S, Hu RJ, et al. Cbl-b regulates the CD28 dependence of T-cell activation. Nature (2000) 403:216-20. doi:10.1038/35003235

6. Naramura M, Jang IK, Kole H, Huang F, Haines D, Gu H. c-Cbl and Cbl-b regulate $\mathrm{T}$ cell responsiveness by promoting ligand-induced TCR down-modulation. Nat Immunol (2002) 3:1192-9. doi:10.1038/ni855
$(45,46)$ and humans $(47,48)$. Therefore, exacerbation of disease in Cbl- $b^{-/-}$mice may be due to a combination of B cell and mast cell dysregulation, correlated with IgE crosslinking of FceRI during aerosol challenge. As discussed previously, Cbl-b has also been shown to play important roles in mediating anergy induction in other lymphoid subsets in addition to B cells and mast cells, such as NK and NK-T cells. In the experimental animal model utilized in this study $\left(\mathrm{Cbl}-\mathrm{b}^{-/-}\right)$, all leukocyte subsets are deficient in Cbl-b expression, meaning that there is probably a pleiotropic effect of Cbl-b deficiency on global cellular immune responses in this inhaled allergy model. Further studies are required to assess the contribution of Cbl-b deficiency on the function of other immune cell subsets in the context of OVA-induced AAD and LIT.

In conclusion, $\mathrm{Cbl}^{-\mathrm{b}^{-/}}$mice exhibit increased inflammatory responses to OVA-induced allergic airway inflammation, including exacerbations in disease outcomes at both AAD and LIT timepoints, and increases in T cell chemokine and proinflammatory $\mathrm{T}_{\mathrm{H}} 2$ cytokines in the BAL. Conversely, Cbl- $\mathrm{b}^{-/-}$mice did not show modulations in $\mathrm{T}$ or B cells in local or systemic compartments during AAD or LIT, nor was there a significant modulation in serum IgE production at either timepoint. Finally, Cbl-b did exhibit a increase in a possibly polyclonal cell population with an effector $\mathrm{T}$ cell phenotype in the BAL during $\mathrm{AAD}$, suggesting a dysregulation of $\mathrm{T}$ cell responses during acute disease. These findings indicate a role for Cbl-b in the regulation and resolution of allergic airway responses, along with suggesting a correlation between disease severity and impaired regulatory $\mathrm{T}$ cell functions.

\section{AUTHOR CONTRIBUTIONS}

All authors assisted in data collection and analysis, and assisted in manuscript preparation and revision. WC, CS, RC, and RT designed the experiments. RC, CS, SK, and RT provided reagents, equipment, and experimental animals. WC, LG, AS, ES, and EW performed the experiments. WC, CS, and RT wrote the manuscript.

\section{FUNDING}

This work was supported by NIH R01 HL43573 and NIH R01 HL031237.

7. Heissmeyer V, Macian F, Im SH, Varma R, Feske S, Venuprasad K, et al. Calcineurin imposes $\mathrm{T}$ cell unresponsiveness through targeted proteolysis of signaling proteins. Nat Immunol (2004) 5:255-65. doi:10.1038/ni1047

8. Qiao G, Li Z, Molinero L, Alegre ML, Ying H, Sun Z, et al. T-cell receptor-induced NF-kappaB activation is negatively regulated by E3 ubiquitin ligase Cbl-b. Mol Cell Biol (2008) 28:2470-80. doi:10.1128/MCB.01505-07

9. Bachmaier K, Krawczyk C, Kozieradzki I, Kong YY, Sasaki T, OliveiraDos-Santos A, et al. Negative regulation of lymphocyte activation and autoimmunity by the molecular adaptor Cbl-b. Nature (2000) 403:211-6. doi: $10.1038 / 35003228$

10. Paolino M, Choidas A, Wallner S, Pranjic B, Uribesalgo I, Loeser S, et al. The E3 ligase Cbl-b and TAM receptors regulate cancer metastasis via natural killer cells. Nature (2014) 507:508-12. doi:10.1038/nature12998

11. Kojo S, Elly C, Harada Y, Langdon WY, Kronenberg M, Liu YC. Mechanisms of NKT cell anergy induction involve Cbl-b-promoted monoubiquitination of CARMA1. Proc Natl Acad Sci U S A (2009) 106:17847-51. doi:10.1073/ pnas.0904078106 
12. Kitaura Y, Jang IK, Wang Y, Han YC, Inazu T, Cadera EJ, et al. Control of the B cell-intrinsic tolerance programs by ubiquitin ligases $\mathrm{Cbl}$ and Cbl-b. Immunity (2007) 26:567-78. doi:10.1016/j.immuni.2007.03.015

13. Zhang J, Chiang YJ, Hodes RJ, Siraganian RP. Inactivation of c-Cbl or Cbl-b differentially affects signaling from the high affinity IgE receptor. J Immunol (2004) 173:1811-8. doi:10.4049/jimmunol.173.3.1811

14. Krawczyk CM, Jones RG, Atfield A, Bachmaier K, Arya S, Odermatt $B$, et al. Differential control of CD28-regulated in vivo immunity by the E3 ligase Cbl-b. J Immunol (2005) 174:1472-8. doi:10.4049/ jimmunol.174.3.1472

15. Wohlfert EA, Callahan MK, Clark RB. Resistance to CD4+CD25+ regulatory $\mathrm{T}$ cells and TGF-beta in Cbl-b-/- mice. JImmunol (2004) 173:1059-65. doi:10.4049/jimmunol.173.2.1059

16. Wohlfert EA, Gorelik L, Mittler R, Flavell RA, Clark RB. Cutting edge: deficiency in the E3 ubiquitin ligase Cbl-b results in a multifunctional defect in $\mathrm{T}$ cell TGF-beta sensitivity in vitro and in vivo. J Immunol (2006) 176:1316-20. doi:10.4049/jimmunol.176.3.1316

17. Schramm CM, Puddington L, Wu C, Guernsey L, Gharaee-Kermani M, Phan SH, et al. Chronic inhaled ovalbumin exposure induces antigen-dependent but not antigen-specific inhalational tolerance in a murine model of allergic airway disease. Am J Pathol (2004) 164:295-304. doi:10.1016/ S0002-9440(10)63119-7

18. Gavett SH, Chen X, Finkelman F, Wills-Karp M. Depletion of murine CD4+ $\mathrm{T}$ lymphocytes prevents antigen-induced airway hyperreactivity and pulmonary eosinophilia. Am J Respir Cell Mol Biol (1994) 10:587-93. doi:10.1165/ ajrcmb.10.6.8003337

19. Carson WF IV, Guernsey LA, Singh A, Vella AT, Schramm CM, Thrall RS. Accumulation of regulatory $\mathrm{T}$ cells in local draining lymph nodes of the lung correlates with spontaneous resolution of chronic asthma in a murine model. Int Arch Allergy Immunol (2008) 145:231-43. doi:10.1159/000109292

20. Qiao G, Ying H, Zhao Y, Liang Y, Guo H, Shen $H$, et al. E3 ubiquitin ligase Cbl-b suppresses proallergic $\mathrm{T}$ cell development and allergic airway inflammation. Cell Rep (2014) 6:709-23. doi:10.1016/j.celrep.2014.01.012

21. Yiamouyiannis CA, Schramm CM, Puddington L, Stengel P, BaradaranHosseini E, Wolyniec WW, et al. Shifts in lung lymphocyte profiles correlate with the sequential development of acute allergic and chronic tolerant stages in a murine asthma model. Am J Pathol (1999) 154:1911-21. doi:10.1016/ S0002-9440(10)65449-1

22. Renz H, Smith HR, Henson JE, Ray BS, Irvin CG, Gelfand EW. Aerosolized antigen exposure without adjuvant causes increased $\operatorname{IgE}$ production and increased airway responsiveness in the mouse. J Allergy Clin Immunol (1992) 89:1127-38. doi:10.1016/0091-6749(92)90296-E

23. Hamelmann E, Gelfand EW. IL-5-induced airway eosinophilia - the key to asthma? Immunol Rev (2001) 179:182-91. doi:10.1034/j.1600-065X.2001.790118.x

24. Ngoc PL, Gold DR, Tzianabos AO, Weiss ST, Celedon JC. Cytokines, allergy, and asthma. Curr Opin Allergy Clin Immunol (2005) 5:161-6. doi:10.1097/01. all.0000162309.97480.45

25. Broide DH. Immunologic and inflammatory mechanisms that drive asthma progression to remodeling. J Allergy Clin Immunol (2008) 121:560-70; quiz 571-562. doi:10.1016/j.jaci.2008.01.031

26. Doganci A, Sauer K, Karwot R, Finotto S. Pathological role of IL-6 in the experimental allergic bronchial asthma in mice. Clin Rev Allergy Immunol (2005) 28:257-70. doi:10.1385/CRIAI:28:3:257

27. Doganci A, Eigenbrod T, Krug N, De Sanctis GT, Hausding M, Erpenbeck VJ, et al. The IL-6R alpha chain controls lung CD4+CD25+ Treg development and function during allergic airway inflammation in vivo. J Clin Invest (2005) 115:313-25. doi:10.1172/JCI22433C1

28. Wan S, Xia C, Morel L. IL-6 produced by dendritic cells from lupus-prone mice inhibits CD4+CD25+ T cell regulatory functions. J Immunol (2007) 178:271-9. doi:10.4049/jimmunol.178.1.271

29. Rothenberg ME, Hogan SP. The eosinophil. Annu Rev Immunol (2006) 24:147-74. doi:10.1146/annurev.immunol.24.021605.090720

30. Takatsu K, Nakajima H. IL-5 and eosinophilia. Curr Opin Immunol (2008) 20:288-94. doi:10.1016/j.coi.2008.04.001
31. Heissmeyer V, Rao A. E3 ligases in T cell anergy - turning immune responses into tolerance. Sci STKE (2004) 2004:e29. doi:10.1126/stke.2412004pe29

32. Mueller DL. E3 ubiquitin ligases as T cell anergy factors. Nat Immunol (2004) 5:883-90. doi:10.1038/ni1106

33. Jeon MS, Atfield A, Venuprasad K, Krawczyk C, Sarao R, Elly C, et al. Essential role of the E3 ubiquitin ligase Cbl-b in T cell anergy induction. Immunity (2004) 21:167-77. doi:10.1016/j.immuni.2004.07.013

34. Hanlon A, Jang S, Salgame P. Cbl-b differentially regulates activation-induced apoptosis in T helper 1 and T helper 2 cells. Immunology (2005) 116:507-12. doi:10.1111/j.1365-2567.2005.02252.x

35. Huang F, Kitaura Y, Jang I, Naramura M, Kole HH, Liu L, et al. Establishment of the major compatibility complex-dependent development of CD4+ and CD8+ T cells by the Cbl family proteins. Immunity (2006) 25:571-81 doi:10.1016/j.immuni.2006.08.021

36. Sohn HW, Gu H, Pierce SK. Cbl-b negatively regulates B cell antigen receptor signaling in mature B cells through ubiquitination of the tyrosine kinase Syk. J Exp Med (2003) 197:1511-24. doi:10.1084/jem.20021686

37. Qiao G, Lei M, Li Z, Sun Y, Minto A, Fu YX, et al. Negative regulation of CD40mediated B cell responses by E3 ubiquitin ligase Casitas-B-lineage lymphoma protein-B. J Immunol (2007) 179:4473-9. doi:10.4049/jimmunol.179.7.4473

38. Arron JR, Vologodskaia M, Wong BR, Naramura M, Kim N, Gu H, et al. A positive regulatory role for $\mathrm{Cbl}$ family proteins in tumor necrosis factor-related activation-induced cytokine (trance) and CD40L-mediated Akt activation. J Biol Chem (2001) 276:30011-7. doi:10.1074/jbc.M100414200

39. Shao Y, Yang C, Elly C, Liu YC. Differential regulation of the B cell receptor-mediated signaling by the E3 ubiquitin ligase Cbl. J Biol Chem (2004) 279:43646-53. doi:10.1074/jbc.M404082200

40. Kuhn R, Rajewsky K, Muller W. Generation and analysis of interleukin-4 deficient mice. Science (1991) 254:707-10. doi:10.1126/science.1948049

41. Hamelmann E, Takeda K, Schwarze J, Vella AT, Irvin CG, Gelfand EW. Development of eosinophilic airway inflammation and airway hyperresponsiveness requires interleukin-5 but not immunoglobulin E or B lymphocytes. Am J Respir Cell Mol Biol (1999) 21:480-9. doi:10.1165/ajrcmb.21.4.3659

42. Singh A, Carson WF IV, Secor ER Jr, Guernsey LA, Flavell RA, Clark RB, et al. Regulatory role of B cells in a murine model of allergic airway disease. J Immunol (2008) 180:7318-26. doi:10.4049/jimmunol.180.11.7318

43. Qu X, Sada K, Kyo S, Maeno K, Miah SM, Yamamura H. Negative regulation of FcepsilonRI-mediated mast cell activation by a ubiquitin-protein ligase Cbl-b. Blood (2004) 103:1779-86. doi:10.1182/blood-2003-07-2260

44. Gustin SE, Thien CB, Langdon WY. Cbl-b is a negative regulator of inflammatory cytokines produced by IgE-activated mast cells. J Immunol (2006) 177:5980-9. doi:10.4049/jimmunol.177.9.5980

45. Taube C, Wei X, Swasey CH, Joetham A, Zarini S, Lively T, et al. Mast cells, Fc epsilon RI, and IL-13 are required for development of airway hyperresponsiveness after aerosolized allergen exposure in the absence of adjuvant. J Immunol (2004) 172:6398-406. doi:10.4049/jimmunol.172.10.6398

46. Yu M, Tsai M, Tam SY, Jones C, Zehnder J, Galli SJ. Mast cells can promote the development of multiple features of chronic asthma in mice. J Clin Invest (2006) 116:1633-41. doi:10.1172/JCI25702

47. Bradding P, Walls AF, Holgate ST. The role of the mast cell in the pathophysiology of asthma. J Allergy Clin Immunol (2006) 117:1277-84. doi:10.1016/j. jaci.2006.02.039

48. Krishnaswamy G, Ajitawi O, Chi DS. The human mast cell: an overview. Methods Mol Biol (2006) 315:13-34. doi:10.1385/1-59259-967-2:013

Conflict of Interest Statement: The authors declare that the research was conducted in the absence of any commercial or financial relationships that could be construed as a potential conflict of interest.

Copyright ( 2015 Carson, Guernsey, Singh, Secor, Wohlfert, Clark, Schramm, Kunkel and Thrall. This is an open-access article distributed under the terms of the Creative Commons Attribution License (CC BY). The use, distribution or reproduction in other forums is permitted, provided the original author(s) or licensor are credited and that the original publication in this journal is cited, in accordance with accepted academic practice. No use, distribution or reproduction is permitted which does not comply with these terms. 